\title{
Research \\ The effects of levonorgestrel intra-uterine system on adenomyosis and endometriosis: A three year follow up study
}

\author{
DasMahapatra Pramathes ${ }^{1}$, Bhattacharyya Partha ${ }^{1}$, DasMahapatra Pritha ${ }^{1}$
}

Sri Lanka Journal of Obstetrics and Gynaecology 2010; 32: 27-33

\begin{abstract}
Objective: To study effects of levonorgestrel intra-uterine system (LNG-IUS) on adenomyosis with and without endometriosis.

Design: Fifty-eight women with a confirmed diagnosis of adenomyosis after exclusion of confounding factors, and detection or exclusion of endometriosis were selected. They were categorized into group A (only adenomyosis, $\mathrm{n}=44$ ) and group B (adenomyosis plus endometriosis, pre-treated by laparoscopic surgery, $\mathrm{n}=14$ ) received LNG-IUS between July 2004 and January 2006 and were followed up on five different parameters.
\end{abstract}

Results: Analysis of three years' follow up shows mean reduction of different variables in groups A and B as dysmenorrhoea (visual analogue scale) $98.2 \pm 3.9 \%$ and $98.3 \pm 3.7 \%$ $(\mathrm{p}<0.0001)$ menstrual bleeding (blood-loss assessment chart) $92.2 \pm 11.2 \%$ and $85.0 \pm 17.5 \%$ $(\mathrm{p}<0.0001)$, chronic pelvic pain (pain-calendar) $98.8 \pm 2.7 \%$ and $96.4 \pm 4.9 \%(\mathrm{p}<0.0001)$; uterine volume $27.8 \pm 9.0 \%$ and $28.7 \pm 9.6 \%(\mathrm{p}<0.0005)$ maximum endo-myometrial junctional-zone thickness $30.2 \pm 7.9 \%$ and $26.0 \pm 4.8 \%(p<0.0005)$. Effects on groups $\mathrm{A}$ and $\mathrm{B}$ were comparable. Other observations were - amenorrhoea- $27.5 \%$, intermenstrual bleeding-37.3\% and expulsion- $6.9 \%$.

Conclusion: LNG-IUS is equally effective for long-term conservative management of both adenomyosis alone and with co-existent endometriosis.

Key words: Adenomyosis, endometriosis, conservative treatment, LNG-IUS.

\footnotetext{
${ }^{1}$ Spectrum Clinic and Endoscopy Research Institute, Kolkata, India.

Correspondence: DasMahapatra Pramathes

E-mail:promathe@cal.vsnl.net.in
}

\section{Introduction}

Conservative management of symptomatic adenomyosis focuses on relieving symptoms with the ultimate aim to postpone or avoid hysterectomy. This has become the standard approach for a woman who is yet to complete her family or too young for hysterectomy or desires to conserve her uterus. Keeping pace with rapidly evolving attitude among women to avoid hysterectomy, a number of conservative modalities, e.g. levonorgestrel intra-uterine system (LNG-IUS), intra-uterine danazol, uterine artery embolization, have emerged in the last decade and proved effective for treating adenomyosis.

LNG-IUS was introduced in the mid 70s as a longacting intra-uterine contraceptive device loaded with $52 \mathrm{mg}$ of LNG and releasing $20 \mu \mathrm{g}$ per day through a rate limiting surface membrane ${ }^{1}$. Fedele et al pioneered the utilization of LNG-IUS for controlling menorrhagia related to adenomyosis and showed that it was effective and did not produce much adverse effects ${ }^{2}$. Subsequent studies suggested that the locally released levonorgestrel inhibits endometrial proliferation by suppressing expressions of vascular endothelial growth factor and anti-apoptotic protein bcl-2 in endometrium $^{3,4}$. It was also proved by ultrasonography that LNG-IUS causes reduction of endometrial thickness and blood flow in subendometrial branches of spiral arteries ${ }^{5}$. Other clinical studies also proved the efficacy of LNG-IUS in reducing adenomyosis related menstrual blood loss, dysmenorrhoea, uterine size and thickness of endo-myometrial junction to a significant extent $t^{6,7}$.

It is a common observation that adenomyosis is strongly associated with endometriosis; $20 \%$ of women with adenomyosis may have endometriosis ${ }^{8}$ whereas adenomyosis is present in $79-90 \%$ of women with endometriosis ${ }^{9}$. Both of these conditions are progressive, estrogen dependent and their symptoms viz., dysmenorrhoea and chronic pelvic pain often overlap. Interestingly, this association was not considered in the previous studies though LNG-IUS has proved beneficial in relieving symptoms of isolated endometriosis in short-term studies ${ }^{10,11}$ and by one systemic review ${ }^{12}$. 
The objectives of our study were to observe the effects of LNG-IUS on different subjective and objective parameters of adenomyosis with and without associated endometriosis, to study whether the clinical impact of LNG-IUS differs in the two settings adenomyosis alone and adenomyosis with co-existent endometriosis and to assess long term compliance.

\section{Materials and methods}

This is a prospective cohort study on 58 selected women with either adenomyosis only (group A, n=44) or adenomyosis plus co-existent endometriosis (group B, n=14) treated with LNG-IUS between July 2004 and
January 2006. Comparison was made between the pretreatment baseline status and 36 months' posttreatment status of the following parameters: dysmenorrhoea, menstrual bleeding, chronic pelvic pain, uterine volume and maximal thickness of endomyometrial junctional zone $\left(\mathrm{Jz}_{\mathrm{Max}}\right)$ in two groups separately. The principles of patient selection were, (a) confirmed diagnosis of adenomyosis by magnatic resonance imaging(MRI), (b) exclusion of confounding factors (viz. fibroids, uterine polyps), (c) detection or exclusion of co-existent endometriosis, and (d) suitability for LNG-IUS insertion. The sequence of the selection is presented in the consort flow chart (Figure 1) and the pertinent points are explained here briefly.

\section{Figure 1. Consort flow chart showing selection of the patients}

Eligibility assessment on clinical and reproductive profile $(\mathrm{n}=112)$

TVS of uterus ( $=112)$ : Diagnostic criteria for adenomyosis not fulfilled $=10$, Fibroid \pm adenomyosis $=11$. Remaining 91 were advised MRI

MRI of uterus ( $\mathrm{n}=91$ ): Diagnostic criteria not fulfilled and/or fibroid $=8, \mathrm{UCL}>14 \mathrm{~cm}=4$. Remaining 79 were counseled for LNG-IUS

Counselling $(n=79)$ : Preferred hysterectomy $=17$, wanted medical treatment $=2$, undecided about completing family $=2$. Remaining 58 enrolled into study

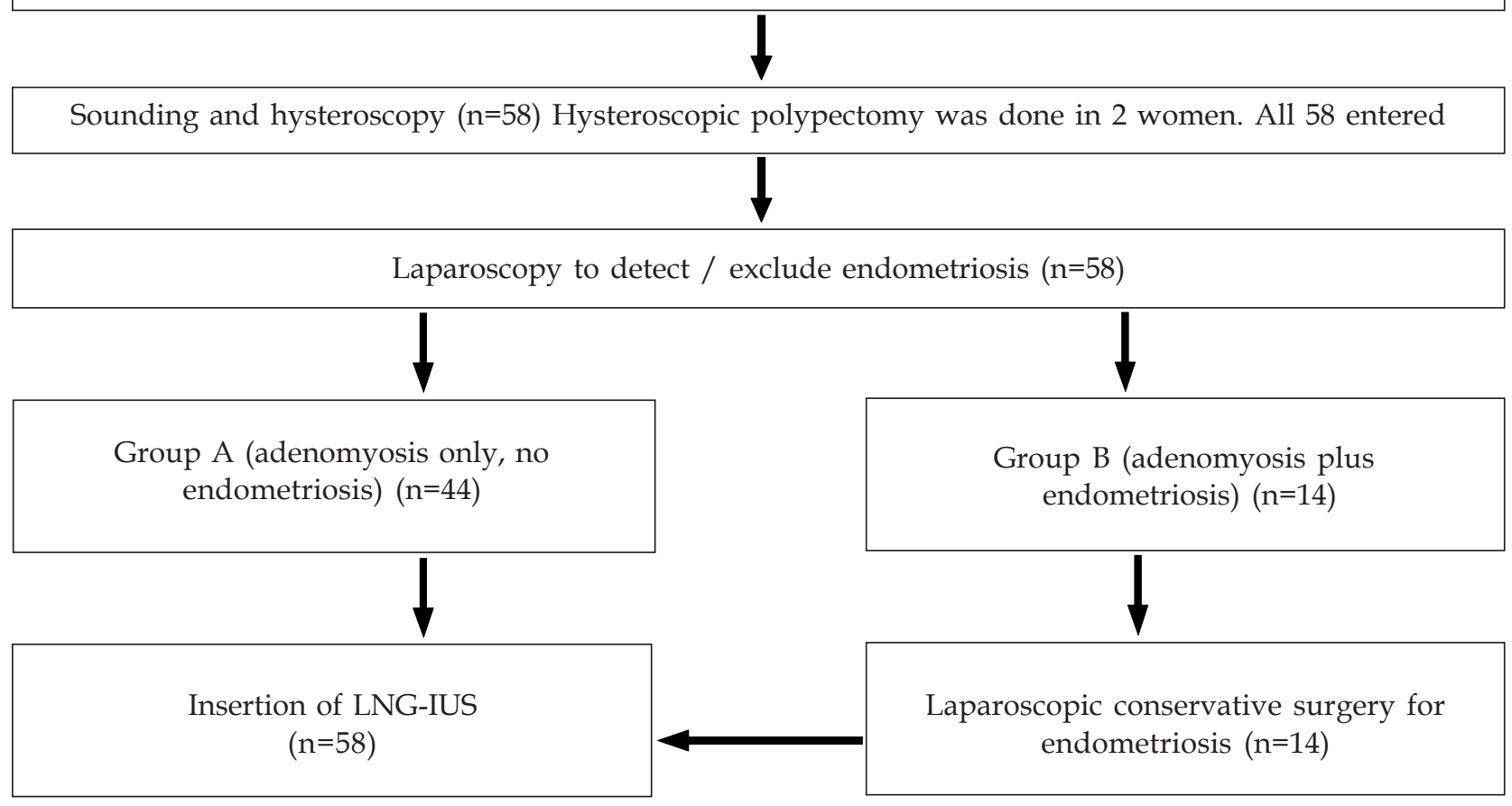


Preliminary criteria for considering further workup for this study were - (a) complaint of any one or combination of dysmenorrhoea, excessive menstrual bleeding and chronic pelvic pain for more than 6 months, (b) tender and bulky uterus on examination, (c) no desire of further conception, (d) absence of any overt pelvic inflammatory disease, and (e) cervical dysplasia excluded by cervical cytology evaluation. Transvaginal sonographic (TVS) features used as diagnostic criteria were, ill defined heterogeneous and hypoechogenic echo texture within the myometrium, anechoic lakes (1-3 $\mathrm{mm})$, indistinct endo-myometrial border and sub-endometrial halo-thickening ${ }^{13,14}$. Magnetic resonance imaging (MRI) was done and following criteria were used for diagnosing adenomyosis (a) $\mathrm{Jz}_{\mathrm{Max}}$ more than $12 \mathrm{~mm}$ or (b) $\mathrm{Jz}_{\mathrm{Max}}$ between 8-12 $\mathrm{mm}$ with high-signal-intensity foci in T2 weighed images ${ }^{15,16,17}$. We excluded women with uterine cavities longer than $14 \mathrm{~cm}$. The cut-off value was taken anticipating a higher likelihood of expulsion of the costly device from a large uterine cavity. We counseled the patients on the non-permanent nature of LNG-IUS as treatment of adenomyosis, individually variable effects on symptoms, chances of expulsion and side effects and concomitant contraceptive benefit with a failure rate of $0.7 \%{ }^{18}$. Fifty-eight patients consented to receive LNG-IUS; their clinical and demographic profile is depicted in Table 1.

Table 1. Salient demographic and clinical features of patients who received LNG-IUS

\begin{tabular}{lcr}
\hline Characteristics & $\begin{array}{c}\text { Group A }(n=44) \\
\text { Only adenomyosis }\end{array}$ & $\begin{array}{c}\text { Group B }(n=14) \\
\text { Adenomyosis plus endometriosis }\end{array}$ \\
\hline Mean age in years (SD) & $37.9(5.8)$ & $36.9(5.3)$ \\
\hline Mean body weight in Kg (SD) & $62.8(11.4)$ & $61.5(7.4)$ \\
\hline Reproductive profile & $2(4.5 \%)$ & nil \\
No child & $23(52.3 \%)$ & $9(64.28 \%)$ \\
One child & $19(43.2 \%)$ & $5(35.7 \%)$ \\
Two/more children & &
\end{tabular}

\section{Education level}

Illiterat

School education

Graduate

Masters or beyond

Number of women with symptoms and their mean duration in months
Dysmenorrhoea
$36(81.8 \%) ; 23 \mathrm{~m}$
$13(92.9 \%) ; 22 \mathrm{~m}$
Excessive menstrual bleeding
$37(84.1 \%) ; 13 \mathrm{~m}$
$8(57.1 \%) ; 11 \mathrm{~m}$
Chronic pelvic pain
$12(27.3 \%) ; 14 \mathrm{~m}$
$9(64.3 \%) ; 10 \mathrm{~m}$

Mean uterine cavity length in $\mathrm{cm}$ (SD)

$9.2(1.7)$

$9.2(1.8)$

Mean uterine vol. in $\mathrm{ml}$ (SD)

$166(60.1)$

$157.6(46)$

Mean $\mathrm{Jz}_{\max }$ in $\mathrm{mm}(\mathrm{SD})$

$12.3(2.2)$

$12.3(2.7)$

Women with endometriosis

none 


\section{Pre-treatment assessment}

Dysmenorrhoea was assessed by 'visual analogue score' ${ }^{\prime 19}$. Menstrual flow was assessed by number of pads required per cycle recorded in a 'pictorial blood-loss assessment chart'20. Chronic pelvic pain was assessed by 'pain calendar' - the women were asked to mark the days, which were most painful in a given calendar. The uterine volume was measured by MRI applying prolate-ellipsoid formula (volume = length $\times$ breadth $\times$ thickness $\times 0.523$ ).

\section{Surgical procedure}

The pre-insertion procedure comprised of uterine sounding, hysteroscopy, diagnostic laparoscopy and laparoscopic conservative surgery by high-frequency ultrasound when endometriosis was present. This was followed by insertion of LNG-IUS - all under general anaesthesia.

Uterine sounding was done to verify the MRI measurement of uterine cavity length. They corroborated within $\pm 5 \%$; the MRI measurement was documented in the record. Hysteroscopy was done with $3 \mathrm{~mm} 30^{\circ}$ hysteroscope using 5\% dextrose as distending medium. Two women had uterine polyps, which were excised after changing the media to glycine. Diagnostic laparoscopy was done using 10 $\mathrm{mm} 0^{\circ}$ laparoscope through an infra-umbilical vertical incision.

Forty-four women with only adenomyosis (group A) were inserted LNG-IUS following the standard procedure after the diagnostic laparoscopy and discharged in the same evening. Fourteen women (group B) had co-existent endometriosis which was staged by 'revised American Fertility Society (rAFS) score $^{\prime 21}$. Four women had stage II endometriosis (rAFS score 21-30); five stage III (rAFS score 31-40) and five stage IV (rAFS score above 40). The conser-vative surgery was done by the first author, who has more than 20 years experience in this procedure. The procedure comprised of excision and lysis of adhesions and desiccation of peritoneal and superficial ovarian endometriosis and excision of cyst wall in endometriomas. LNG-IUS was inserted after completion of laparoscopic surgery. The patients were discharged on the 2 nd post-operative day. No major intraoperative or post-operative complications related to hysteroscopy or laparoscopy or insertion of LNG-IUS occurred in either group.

Follow up visits were scheduled after one, three, six, nine, and twelve months after the insertion and every six monthly thereafter. The women were advised to inform immediately of any complications such as inter-menstrual or excessive vaginal bleeding, persistence or aggravation of pain or expulsion of the device.

Dysmenorrhoea, menstrual bleeding and chronic pelvic pain were assessed at each visit using the reference systems described earlier. The body weight, blood pressure and incidence of side effects - intermenstrual bleeding, breast tenderness, arthralgia, depression and swelling of legs were recorded. MRI was done 36 months after insertion to measure the uterine volume and $\mathrm{Jz}_{\text {Max }}$. Two women (3.4\%) discontinued at 4 th and 7 th month for persistent symptoms and requested hysterectomy. The device expelled spontaneously in four women $(6.9 \%)$ by 3 rd month. One $(1.7 \%)$ woman was lost to follow up after 1st month. Fifty-one patients (group A - 39, group B 12) completed 36 months follow up, an overall continuation rate of $87.9 \%$.

\section{Results}

Table 2A shows the change of mean values and percentage reduction of three symptom parameters with their statistical significance. The p-value obtained by Friedman test for each parameter in each group is significant. Table 2B shows the change of mean uterine volume and $\mathrm{Jz}_{\mathrm{Max}}$, percentage reduction and their statistical significance. The two-tailed p-value obtained in each group is highly significant.

Table 3 shows that overall $27.5 \%$ women experienced persistent amenorrhoea for more than 36 months. Another $9.8 \%$ had temporary amenorrhoea lasting for an average of 7.6 months. The incidence of intermenstrual bleeding was $37.9 \%$ and $7.8 \%$ after 3 and 36 months respectively. Four patients had weight gain $>10 \%$ between 9 and 36 months post-insertion. Seven patients had new-onset transient large-joint arthralgia without any evidence of active arthritis; they were controlled with simple analgesics. We also wanted to see whether a large uterine cavity had any effect on the treatment outcome. Forty-eight women (group A - 38, group B - 10) had uterine cavity lengths up to $10 \mathrm{~cm}$ and ten women (group A - 6, group B -4) had uterine cavity lengths between 10.1 and $14 \mathrm{~cm}$. Amongst those patients with uterine cavity more than $10 \mathrm{~cm}$, one lost to follow up; expulsion occurred in three $(33.3 \%)$ and one woman $(11.1 \%)$ discontinued for persistent symptoms. On contrary, in those with uterine cavity lengths up to $10 \mathrm{~cm}(\mathrm{n}=48)$, only one patient had expulsion and one discontinued. This finding may prove a limitation of using this device for women with adenomyosis causing an enlargement of the uterine cavity. 
Table 2A. Relief of dysmenorrhoea, menstrual bleeding and chronic pelvic pain after 36 months Group A (only adenomyosis, n=39) and Group B (adenomyosis with endometriosis, n=12)

\begin{tabular}{|c|c|c|c|c|c|c|}
\hline \multirow{2}{*}{$\begin{array}{l}\text { Parameter } \\
\text { Scale of measurement }\end{array}$} & \multicolumn{2}{|c|}{$\begin{array}{l}\text { Dysmenorrhoea } \\
\text { Visual analogue scale }\end{array}$} & \multicolumn{2}{|c|}{$\begin{array}{l}\text { Menstrual bleeding } \\
\text { No. of Pads/cycle }\end{array}$} & \multicolumn{2}{|c|}{$\begin{array}{l}\text { Chronic pelvic pain } \\
\text { Painful days/month }\end{array}$} \\
\hline & Group A & Group B & Group A & Group B & Group A & Group B \\
\hline Pre-insertion mean (SD) & $10(0)$ & $10(0)$ & $29.4(20.7)$ & $19.6(13.9)$ & $25.1(6.3)$ & $26.6(4.5)$ \\
\hline Mean (SD) at 36 months & $0.2(0.4)$ & $0.2(0.4)$ & $1.5(1.2)$ & $1.8(1.2)$ & $0.4(0.9)$ & $1.0(1.3)$ \\
\hline$\%$ reduction $(\mathrm{SD})$ & $98.2(3.9)$ & $98.3(3.7)$ & $92.2(11.2)$ & $84(17.5)$ & $98.8(2.7)$ & $96.4(4.9)$ \\
\hline \multicolumn{7}{|c|}{ p value: Friedman test (non-parametric repeated measures ANOVA) } \\
\hline & $<0.0001$ & $<0.0001$ & $<0.0001$ & $<0.0001$ & $<0.0001$ & $<0.0001$ \\
\hline \multicolumn{7}{|c|}{ Post-test $\mathrm{p}$ values (Dunn's multiple comparison test) } \\
\hline 0-1 month & $>0.05$ & $>0.05$ & $>0.05$ & $>0.05$ & $>0.05$ & $>0.05$ \\
\hline 0-3 months & $<0.001$ & $>0.05$ & $<0.001$ & $>0.05$ & $>0.05$ & $>0.05$ \\
\hline 0-6 months & $<0.001$ & $>0.05$ & $<0.001$ & $>0.05$ & $>0.05$ & $>0.05$ \\
\hline 0-9 months & $<0.001$ & $<0.01$ & $<0.001$ & $<0.01$ & $<0.001$ & $<0.05$ \\
\hline 0-12 months & $<0.001$ & $<0.001$ & $<0.001$ & $<0.001$ & $<0.001$ & $<0.05$ \\
\hline 0-18 months & $<0.001$ & $<0.001$ & $<0.001$ & $<0.001$ & $<0.001$ & $<0.01$ \\
\hline 0-24 months & $<0.001$ & $<0.001$ & $<0.001$ & $<0.001$ & $<0.001$ & $<0.01$ \\
\hline 0-30 months & $<0.001$ & $<0.001$ & $<0.001$ & $<0.001$ & $<0.001$ & $<0.01$ \\
\hline $0-36$ months & $<0.001$ & $<0.001$ & $<0.001$ & $<0.001$ & $<0.001$ & $<0.01$ \\
\hline
\end{tabular}

Table 2B. Reduction of uterine volume and maximal junctional zone thickness $\left(\mathrm{Jz}_{\mathrm{Max}}\right)$ after 36 months' follow up

Group A (only adenomyosis, n=39) and Group B (adenomyosis with endometriosis, n=12)

\begin{tabular}{|c|c|c|c|c|}
\hline \multirow[t]{2}{*}{ Parameter } & \multicolumn{2}{|c|}{ Uterine volume (ml) } & \multicolumn{2}{|c|}{ Maximal junctional zone thickness (mm) } \\
\hline & Group A & Group B & Group A & Group B \\
\hline Pre-insertion mean (SD) & $166.0(60.1)$ & $157.6(46)$ & $12.3(2.2)$ & $12.3(2.7)$ \\
\hline Mean (SD) at 36 months & $121.0(46.6)$ & $10.3(27.4)$ & $8.6(1.9)$ & $9.1(2.2)$ \\
\hline$\%$ reduction $(\mathrm{SD})$ & $27.8(9.0)$ & $28.7(9.6)$ & $30.2(7.9)$ & $26.0(4.7)$ \\
\hline \multicolumn{5}{|c|}{ Two-tailed p value: (Wilcoxin matched pairs signed-ranks test) } \\
\hline & $<0.0001$ & $<0.0001$ & $<0.0005$ & $<0.0005$ \\
\hline
\end{tabular}


Table 3. Other beneficial and side effects of LNG-IUS in the two groups after 36 months follow up Group A (only adenomyosis, $\mathbf{n = 3 9 )}$ ) and Group B (adenomyosis with endometriosis, $\mathbf{n = 1 2}$ )

Group A $(n=39) \quad$ Group B $(n=12) \quad$ Total $(n=51)$

1. Amenorrhoea up to 36 months

$11(28.2 \%)$

$3(25 \%)$

$14(27.5 \%)$

2. Inter-menstrual bleeding
0-3 month
15
4
$19(37.3 \%)$
3-6 months
6
2
$8(15.7 \%)$

\begin{tabular}{|c|c|c|c|}
\hline 3. Weight gain $>10 \%$ & $3(7.7 \%)$ & $1(8.3 \%)$ & $4(7.8 \%)$ \\
\hline 4. Arthralgia (no arthritis) & $5(12.8 \%)$ & $2(16.7 \%)$ & $7(13.7 \%)$ \\
\hline $\begin{array}{l}\text { 5. Mood change } \\
\text { (mild depression, irritability) }\end{array}$ & $1(2.6 \%)$ & nil & $1(2.0 \%)$ \\
\hline 6. Mastalgia & $2(5.1 \%)$ & nil & $2(3.9 \%)$ \\
\hline 7. Acne & nil & $1(8.3 \%)$ & $1(2.0 \%)$ \\
\hline 8. Hirsutism & nil & nil & nil \\
\hline
\end{tabular}

\section{Discussion}

Since the work by Fedele ${ }^{2}$, a number of studies, 7,22 have proved the effectiveness of LNG-IUS for treating adenomyosis yet none of these detected or excluded associated endometriosis. We thought this was important, as associated endometriosis might have a significant impact on the clinical outcome. We studied five clinical parameters simultaneously - dysmenorrhoea, menstrual bleeding, chronic pelvic pain, uterine volume and $\mathrm{Jz}_{\text {Max. }}$ The duration of our study was 36 months. We conclude that LNG-IUS is an effective treatment for long term conservative management of adenomyosis irrespective of associated endometriosis provided the endometriosis is pre-treated by laparoscopic surgery.

Patients from both groups have experienced significant reduction of all symptom parameters, uterine volume and $\mathrm{Jz}_{\mathrm{Max}}$. There was no significant difference in treatment outcome between the groups A and B - provided the pelvic endometriosis is pretreated with laparoscopic surgery prior to insertion. We achieved a 3-years patient compliance rate of $87.9 \%$. Both TVS and MRI were utilized for diagnosing adenomyosis in spite of their comparable sensitivity ( $74 \%$ vs. $78 \%$ ) and specificity ( $87 \%$ vs. $88 \%$ ) in diagnosing adenomyosis ${ }^{23}$. Pre-insertion diagnostic hysteroscopy was done for all. We believe it should be an integral part of LNG-IUS insertion procedure because it offers direct visual assessment of uterine cavity and endometrium. It is a minimally invasive procedure under local anaesthesia. Hysteroscopic resection of endometrial polyp was done in two women from group A. Laparoscopy is the gold standard for diagnosis of endometriosis. To curtail the effect of co-existent endometriosis on the result of LNG-IUS, it was decided to do diagnostic laparoscopy followed by surgical correction if necessary. Hysterectomy with or without bilateral oophorectomy, though a permanent cure for both adenomyosis and endometriosis, is definitely a surgical, endocrinal and psychological trauma to a woman. LNG-IUS, on the other hand is a reversible treatment with an option for withdrawal. It also offers a contraceptive benefit for sexually active women.

\section{Acknowledgements}

S. Dabriwal and B. Majumder for performing ultrasonography and MRI on the study patients and C. Chakroborty and Sumit Paul for statistical advice.

Sri Lanka Journal of Obstetrics and Gynaecology 


\section{References}

1. Varma R, Sinha D, Gupta JK. Non-contraceptive uses of levonorgestrel-releasing hormone system (LNG-IUS) - A systemic enquiry and overview. Europian Journal of Obstetrics and Gynaecology and Reproductive Biology 2006; 125: 9-28.

2. Fedele L, Bianchi S, Raffaelli, R, Portuese A, Dorta M. Treatment of adenomyosis-associated menorrhagia with a levonorgestrel-releasing intrauterine device. Fertility and Sterility 1997; 68(3): 426-29.

3. Laoag-Fernandez JB, Maruo T, Pakarinen P, Murakoshi $\mathrm{H}$, Spitz IM, Johansson E. Effects of levonorgestrel releasing intra-uterine system on the expression of vascular endothelial growth factor and adrenomodulin in the endometrium in adenomyosis. Human Reproduction 2003; 18: 694-9.

4. Maruo T, Laoag-Fernandez JB, Pakarinen P, Murakoshi $\mathrm{H}$, Spitz IM, Johansson E. Effects of the levonorgestrel releasing intra-uterine system on proliferation and apoptosis in the endometrium. Human Reproduction 2001; 16: $2103-8$.

5. Zalel Y, Shulman A, Lidor A, Achiron R, Mashiach S, Gamazu R. The local progestational effect of the levonorgestrel releasing intra-uterine system: A sonographic and Doppler flow study. Human Reproduction 2002; 17: 2878-80.

6. He SM, Wei MX, Han YH, He LH. Effect of levonorgestrel-releasing intrauterine system in the treatment of adenomyosis. Zhonghua Fu Chan Ke Za Zhi 2005; 40(8): 536-8 .

7. Bragheto AM, Caserta N, Bahamondes L, Petta CA. Effectiveness of the levonorgestrel-releasing intra-uterine system in the treatment of adenomyosis diagnosed and monitored by magnetic resonance imaging. Contraception 2007; 76(3): 159-9.

8. Azziz R. Adenomyosis: Current perspectives. Obstetrics and Gynecological Clinics of North America 1989; 16: 221-35.

9. Kunz G, Beil D, Hupert P, Noe M, Kissler S, Leyendecker G. Adenomyosis in endometriosis - prevalence and impact on fertility. Evidence from magnetic resonance imaging. Human Reproduction 2005; 20(8): 2309-16.

10. Lockhat FB, Emembolu JO, Konje JC. The evaluation of the effectiveness of an intrauterine-administered progestogen (levonorgestrel) in the symptomatic treatment of endometriosis and in the staging of the disease. Human Reproduction 2004; 19(1): 179-84.

11. Deng S, Lang JH, Leng JH, Liu ZF, Sun DW, Zhu L. Effects of levonorgestrel-releasing intrauterine system on pain and recurrence associated with endometriosis and adenomyosis. Zhonghua Fu Chan Ke Za Zhi 2006; 41(10): 664-8.

12. Abou-Setta AM, Al-Inany HG, Farquhar CM. Levonorgestrel-releasing intrauterine device (LNG-IUS) for symptomatic endometriosis following surgery. Cochrane Database 2006; 4: CD005072.

13. Brosens JJ, de Souza NM, Barker FG, Paraschos T, Winstin RML. Endovaginal ultrasonography in the diagnosis of adenomyosis uteri: Identifying the predictive characteristics. American Journal of Obstetrics and Gynecology 1995; 102: 471-4.

14. Reinhold C, Atri M, Mehio A, Zakarian R, Aldia AE, Bret PM. Diffuse uterine adenomyosis: Morphologic criteria and diagnostic accuracy of endovaginal sonography. Radiology 1995; 197(3): 609-14.

15. Reinhold C, Tafazoli F, Wang L. Imaging features of adenomyosis. Human Reproduction Update 1998; 4: 337-49.

16. Reinhold C, Tafazoli F, Mehio A, Uterine adenomyosis: Endovaginal US and MR imaging features with histopathologic correlation. Radiographics 1999; 19: S147-60.

17. Hubert J, Bergin D. Imaging the female pelvis: When should MRI be advised? Applied Radiology 2008; 37(1): 9-24.

18. Blumenthal PD, Trussell J, Singh RS, Guo A, Borenstein J, Dubois RW, et al. Cost-effectiveness of treatments for dysfunctional uterine bleeding in women who need contraception. Contraception 2006; 74: 249-58.

19. Wewers ME, Lowe NK. A critical review of visual analogue scales in the measurement of clinical phenomena. Research in Nursing and Health 1990; 13: 227-36

20. Higham JM, O'Brien PM, Shaw RW. Assessment of menstrual blood loss using a pictorial chart. British Journal of Obstetrics and Gynaecology 1990; 97: 734-9.

21. Revised American Society for Reproductive Medicine classification of endometriosis 1996. Fertility and Sterility 1997; 67: 817-21.

22. Deng S, Lang JH, Leng JH, Liu ZF, Sun DW, Zhu L. Effects of levonorgestrel-releasing intrauterine system on pain and recurrence associated with endometriosis and adenomyosis. Zhonghua Fu Chan Ke Za Zhi 2006; 41(10): 664-8.

23. Dueholm M. Transvaginal ultrasound for diagnosis of adenomyosis: A review. In Arulkumaran S (Ed); Best Practice and Research in Clinical Obstetrics and Gynecology: Elsevier, Philadelphia, USA, 2006; 20: 569-82. 